\title{
Differential reinforcing effects of steady and flickering light on bar pressing in the rat
}

\author{
G. LOWE and D. I. WILLIAMS, The \\ University, Hull, England
}

A previous study showed flickering light to be a more effective reinforcer than steady light for the rat following pretest experience of 10 daily $1 / 2-h$ sessions in a dark box. The present study, using a 15-min pretest period, showed higher response rates for steady light than for flickering light. This reversal cannot be explained in terms of the parameters of the reinforcing stimulus; the previous experience of the animal must also be considered.

Rats show a significant increase over their normal operant level of bar pressing in a Skinner box if a dim light onset is made contingent upon this response (e.g., Kish, 1955). In a previous experiment (Williams \& Lowe, 1967), it was found that after an adaptation period of 10 daily $1 / 2-h$ sessions in a dark box flickering light rather than a steady light produced a greater rate of bar pressing as measured over five daily $1 / 2-h$ experimental sessions. This result was interpreted in favor of the notion that stimulus change represents the crucial reinforcing event in this situation (cf. Kish \& Antonitis, 1955; Forgays \& Levin, 1959), the flickering light, with its greater variability, being seen as constituting a greater stimulus change than the steady light.

A second variable which appears to influence the effectiveness of light as a reinforcer is the animal's pretest experience. Appel \& Hurwitz (1959) found a larger light reinforcement effect when the animal had previously been familiarized with the dark experimental box, and similarly Lowe \& Williams (1968) showed that a longer period of adaptation to the dark experimental box also increased the light reinforcement effect. The present experiment is, therefore, a repetition of the initial study (Williams \& Lowe, 1967), using a shorter pretest period, $15 \mathrm{~min}$ instead of $10 \times 30 \mathrm{~min}$. While it may be expected that the overall effectiveness of both flickering and steady light may be reduced following this shorter baseline session, there is no reason to predict from stimulus change theory any alteration in the relative effectiveness of the two types of response-contingent light as reinforcers. METHOD

The experimental box was soundinsulated and measured $9 \frac{1}{2} \times 8 \frac{1}{2} \times 10$ in., with a metal-bar floor and lined on three walls with aluminum. The end wall had a white Perspex screen 6 $1 \frac{1}{4}$ in. high and the full width of the wall. Three-quarters of an inch below this, and 3 in. above the floor of the box was a single bar, 2 in. wide, extending 1 in. into the box. Frequency and duration of bar pressing were recorded on pen and cumulative recorders. The screen could be evenly illuminated from behind, the level of illumination being matched in each stimulus condition; the me ter reading at a point in the box 3 in. above the bar and 3 in. from the screen being $1.5 \mathrm{ft}-\mathrm{c}$. When either a flickering or steady light was contingent upon a response, it remained on for $1 \mathrm{sec}$, or for as long as the bar was depressed.

Hooded rats, aged between 90-100 days, were used. They were raised and maintained

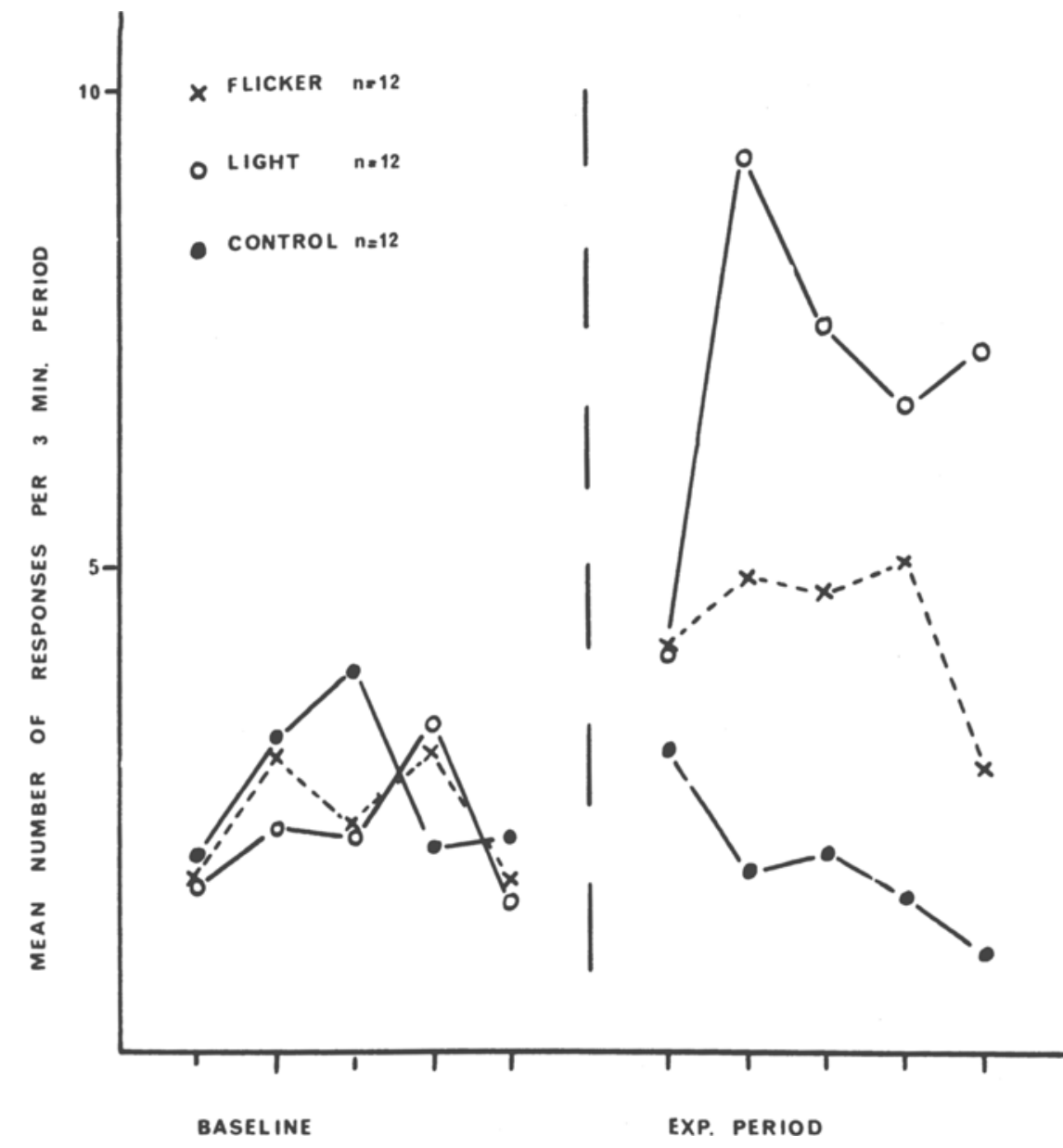

Fig. 1. Average response rates in the baseline and first experimental sessions $(15 \mathrm{~min}$ each).

under normal laboratory illumination with free access to food and water. Each rat was placed in the dark experimental box for $15 \mathrm{~min}$; a bar press produced no change in illumination. Three groups of 12 rats were matched on the basis of response rate during this baseline period. Twenty-four hours later a second 15-min session was run, in which the control group received no light, Group S received steady light, and Group $F$ received flickering light (at 200 flashes per min) contingent upon a bar press. For six rats in each group a further four daily $15-\mathrm{min}$ sessions were run with the same response contingencies.

\section{RESULTS}

Results for the first 2 days are shown in Fig. 1. A one-way analysis of variance of responses on the first session with responsecontingent light showed a significant difference between groups $(F=4.2$, df $=2 / 33, p<.05)$. Although the steadylight group responded more than the flickering-light group, this difference was not significant $(\mathrm{t}=1.29, \mathrm{df}=33, \mathrm{p}>.1)$. The steady-light group responded significantly more than the control group $(t=2.9$, 


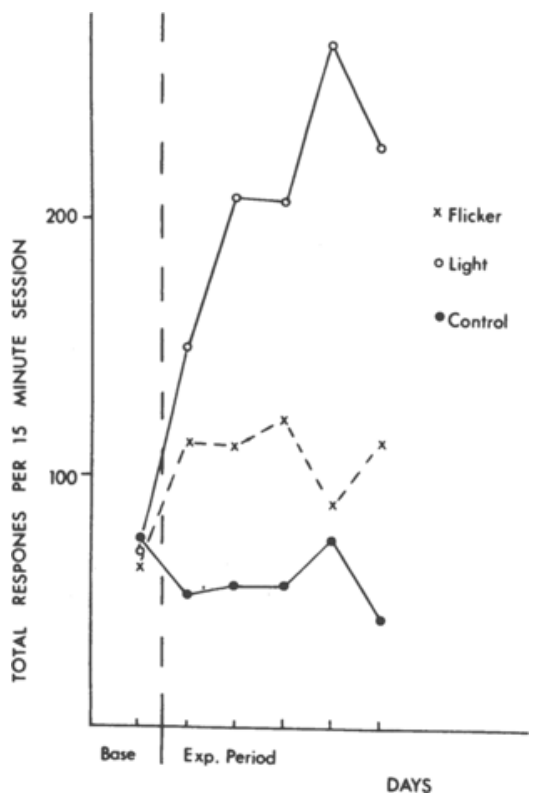

Fig. 2. Response rates in the baseline session (15 $\mathrm{min}$ ) and in the five subsequent experimental sessions (15 min each).

$\mathrm{df}=33, \mathrm{p}<.01$ ), whereas the flickeringlight group did not $(\mathrm{t}=1.59, \mathrm{df}=33$, $\mathrm{p}>$.1). Average response rates for each group over the subsequent four sessions (Fig. 2) were significantly different (Kruskal-Wallis: $\mathrm{H}=10, \mathrm{p}<.01$ ); each group was significantly different from the others (Mann-Whitney: $U$, in each case, $=0$, $\mathrm{p}<.02$ ).

\section{DISCUSSION}

Contrary to expectations, steady light proved to be a more effective reinforcer than flickering light, this being the reverse of the previous finding. The only differences between these two studies were in the length of the test period and length of baseline. The reversal in the effectiveness of these stimuli as reinforcers cannot be dealt with by any theory which seeks to explain the relative effectiveness of sensory reinforcers solely in terms of the characteristics of the reinforcing stimulus, e.g., preference theory (Lockard, 1963), scanning theory (Robinson, 1959), or simple stimulus change theory (Kish \& Antonitis, 1955). It is necessary to take into account the existing state of the animal in relation to the stimulus conditions. For example, Berlyne, Koenig, \& Hirota (1966) argued that reward value of a stimulus is an inverted $U$-shaped function of arousal value, and claimed that the relative effectiveness of novel or familiar stimuli as reinforcers was reversed for animals maintained in a noisy room (high arousal), as compared with animals raised in a quiet room (low arousal). Similarly, Berlyne sees arousal level as being enhanced as a result of a period of deprivation of stimulus change. Thus, the reversal of the effectiveness of steady light and flickering light as reinforcers could be due to differences in arousal level produced by the different periods of pretest familiarization with the apparatus.

\section{REFERENCES}

APPEL, J. B., \& HURWITZ, H. M. B. Studies of light-reinforced behavior: IV. Effects of apparatus familiarization. Psychological Reports, 1959, 5, 355-356.

BERLYNE, D. E., KOENIG, I. D. V., \& HIROTA, T. Novelty, arousal, and the reinforcement of diversive exploration in the rat. Journal of Comparative \& Phy siological Psy chology, 1966, $62,222-226$

FORGAYS, D. G., \& LEVIN, H. Discrimination and reversal learning as a function of change of sensory stimulation. Journal of Comparative \& Physiological Psychology, 1959, 52, 191-194.

KISH, G. B. Learning when the onset of illumination is used as a reinforcing stimulus. Journal of Comparative \& Phy siological Psychology, 1955, 48, 261-264.

KISH, G. B., \& ANTONITIS, J. J. Unconditioned operant behavior in two homozygous strains of mice. Journal of Genetic Psychology, 1956, 88, 121-129.

LOCKARD, R. B. Some effects of light upon the behavior of rodents. Psychological Bulletin, $1963,60,509-529$.

LOWE, G., \& WILLIAMS, D. I. Light reinforcement in the rat: The effects of visual pattern and apparatus familiarization. Animal Behaviour, $1968,16,338-341$.

ROBINSON, J. S. Light onset and termination as reinforcers for rats living under normal light conditions. Psychological Reports, 1959, 5, 793-796.

WILLIAMS, D. I., \& LOWE, G. Bar pressing in the rat as a function of variable visual stimulation. Psychonomic Science, 1967, 7, 231-232.

\section{Disinhibition effect of chlordiazepoxide}

PAUL W. WEDEKING, Department of Pharmacology, The Squibb Institute for Medical Research, New Brunswick, N.J. 08903

Various doses of chlordiazepoxide were administered to rats conditioned to discriminate between two levers for food reinforcement on a multiple FR 25 15-sec time-out schedule. Significant increases in responding during the time-out and in incorrect responses, as well as biphasic effects in correct response rates, were produced at the various dose levels. These results are discussed in terms of a possible disinhibition effect of chlordiazepoxide.

The appetite-stimulating effects of chlordiazepoxide (CDP) were among the first pharmacological observations reported by Randall, Schallek, Heise, Keith, \& Bagdon (1960). Recently, a disinhibition effect of CDP has been suggested by Margules \& Stein (1967), who reported that CDP and other minor tranquilizers markedly increased the occurrence of previously suppressed behavior from inhibition.

A previous report (Wedeking, 1968) described results observed when CDP was administered to rats conditioned on a multiple FR 25 10-sec time-out (TO) schedule; significant increases in response rates were produced during both stimulus presentation and TO. These increases were attributed to both appetite stimulation and a disinh ibition effect of CDP. In the previous experiment (Wedeking, 1968) it was no possible to distinguish between these alternatives. In order to distinguish between these two possibilities, CDP was adminis- tered to rats conditioned on a foodreinforced discrimination $F R$ with TO schedule.

\section{APPARATUS}

The discrimination apparatus was a standard operant conditioning box (Lehigh Valley Electronics) with two conventional rat levers located 6 in. apart on one end of the box. A white stimulus light was positioned $1 \frac{11}{2}$ in. above each lever; to activate either lever, the $S$ had to exert a downward force of $15 \mathrm{~g}$ or more on the lever. A food cup was centered between the two levers. Reinforcement was a single $45 \mathrm{mg}$ Noyes food pellet.

The box was contained in a ventilated sound-attenuated chamber into which white noise was delivered. The complete unit was isolated from programming and monitoring equipment.

\section{SUBJECTS}

Six experimentally naive, male LongEvans rats, 200 days of age at the start of experimentation, served as Ss. They were housed in individual cages with water available ad lib.

\section{PROCEDURE}

Each $S$ was conditioned to discriminate between the two levers by pressing the lever 25 times under the stimulus light (SD) that was lit for a single food pellet reinforcement. Only responses on the lever below the lit stimulus light (correct responses) produced reinforcement while responses on the other lever during $\mathrm{S}^{\mathrm{D}}$ (incorrect responses) were counted but did not effect food delivery. Immediately following reinforcement, there was a 15-sec TO $\left(\mathrm{S}^{\Delta}\right)$ period. If the $\mathrm{S}$ failed to complete 25 correct lever-presses during $2 \mathrm{~min}$, the SD was terminated and a TO 